\title{
Research Paper: Predicting Anxiety Symptoms Based on Confrontation With Existential Issues: The Moderating Role of Defense Mechanisms
}

\author{
Mohammad Ali Besharat' ${ }^{1}$ (D), Hossein Khadem²* (D), Vahid Zarei ${ }^{3}$ (D), Seyed Ali Motavalli Haghi ${ }^{4}$ (i) \\ 1. Department of Psychology, Faculty of Psychology \& Educational Sciences, Tehran University, Tehran, Iran \\ 2. Department of Psychology, Faculty of Psychology \& Educational Sciences, Shahid Beheshti University, Tehran, Iran. \\ 3. Department of Psychology, Faculty of Psychology \& Educational Sciences, Ferdowsi University, Mashhad, Iran. \\ 4. Department of Psychology, University Degli Studi Di Padova, Padova, Italy.
}

\begin{tabular}{|c|c|}
\hline $\begin{array}{l}\text { Use your device to scan } \\
\text { and read the article online }\end{array}$ & Chtation: Besharat, MA., Khadem, H., Zarei, V., \& Motavalli Haghi, SA. (2019). Predicting Anxiety Symptoms Based on \\
\hline 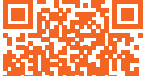 & $\begin{array}{l}\text { Confrontation With Existential Issues: The Moderating Role of Defense Mechanisms. Journal of Practice in Clinical Psychology, } \\
7(4), 235-244 \text {. http://dx.doi.org/10.32598/jpcp.7.4.235 }\end{array}$ \\
\hline 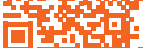 & dol'http://dx.doi.org/10.32598/jpcp.7.4.235 \\
\hline
\end{tabular}

\section{(c) (1) (3)}

Article info:

Received: 10 Apr 2019

Accepted: 23 Aug 2019

Available Online: 01 Oct 2019

Keywords:

Existentialism, Anxiety, Defense mechanisms, Death, Freedom, Responsibility, Loneliness, Meaning

\section{ABSTRACT}

Objective: One of the most common and recent highlighted psychological problems is anxiety symptoms. This study investigated the moderating role of defense mechanisms in the relationship between confrontation with existential issues (death, freedom, isolation, and meaninglessness) and anxiety.

Methods: A total of 389 students (218 men and 171 women) of Ferdowsi University of Mashhad, in the academic year 2017-2018 were randomly selected as the research sample. In this study, anxiety symptoms, death anxiety, loneliness, meaning in life, responsibility, and defense style were measured. The obtained data were analyzed using the Pearson correlation test and stepwise and hierarchical regression analysis.

Results: Mature and immature defense mechanisms moderated the prediction of anxiety symptoms by confrontation with loneliness and responsibility. Neurotic defense mechanisms moderated the prediction of anxiety symptoms by confrontation with death, anxiety, loneliness, and responsibility.

Conclusion: Defense mechanisms affect the amount of relationship between confrontation with existential issues and anxiety.

\section{* Corresponding Author:}

Hossein Khadem, PhD. Candidate

Address: Department of Psychology, Faculty of Psychology \& Educational Sciences, Shahid Beheshti University, Tehran, Iran.

Tel: +98 (939) 4149698

E-mail:ho_khadem@sbu.ac.ir 


\section{Highlights}

- Isolation, death anxiety, lack of freedom and meaninglessness can predict anxiety symptoms.

- Prediction of anxiety symptoms based on confrontation with isolation and responsibility can be moderated by mature and immature defense mechanisms.

- Prediction of anxiety symptoms based on confrontation with death anxiety, isolation, and responsibility can be moderated by neurotic defense mechanism.

\section{Plain Language Summary}

Existential concerns (death, freedom, meaninglessness, and isolation ) are common in all humans. This confrontation naturally produces anxiety. If the anxiety is higher than normal, a variety of mental disorders may develop. Hence, it is important to examine how we confront with existential concerns. Different defense mechanisms reflect how we confront with existential concerns. Defense mechanisms are strategies that we use against problems. Some of them including mature defense mechanism (e.g. humor and optimism) can lead to our health, while other mechanisms like immature and neurotic defense mechanisms (e.g. denial of problems) can lead to various psychological problems. In this study, we found that mature defense mechanisms can reduce the level of anxiety created by isolation and responsibility. In contrast, other defense mechanisms may lead to higher anxiety. There, we can protect ourselves from the burden of responsibility and isolation by using mature defense mechanism. In other words, we can reduce the burden of responsibility, isolation and death anxiety by reducing the use of other defense mechanisms.

\section{Introduction}

roblems related to anxiety are relatively 1 common, and about $30 \%-40 \%$ of people in Western societies at some stages in their life suffer from disruptions that are associated with anxiety (Sadock, Sadock \& Ruiz, 2015).

Anxiety is known as an unpleasant emotion that includes features such as worry, restlessness, and panic. These emotions may occur in humans while responding to unspecific events, situations, people, or phenomena (RoyByrne, 2015; Teimouri, Goetze \& Plonsky, 2019).

Anxiety arises when individuals try to survive, protect, and defend themselves, and the factors that create anxiety are inevitable aspects of the human condition (Langs, 2018). Existential therapists differentiate normal anxiety and neurotic anxiety and consider anxiety a potential source of growth. Normal anxiety is the right response to the event with which a person is faced. Besides, it is not necessary to suppress this kind of anxiety, but it can be used as an incentive to change. In contrast, neurotic anxiety does not fit the situation and usually happens unconsciously and can make people inactive and reduce work performance. They define existential anxiety as a kind of neurotic anxiety. Confrontation with border situations provokes existential anxiety in humans (Cooper, 2016; May \& Yalom, 2005; Zafirides, 2013).
Yalom represented 4 border situations: feeling lonely in the universe, being mortal, losing the meaning in life, and making irreversible decisions. In other words, an individual's confrontation with these situations provokes existential issues (death, loneliness [or being isolated], freedom [or responsibility in life], and meaningless) in humans (Yalom, 1980; Zafirides, 2013).

Inability to the healthy confrontation with existential issues is the leading cause of many mental disorders, including anxiety symptoms. Death anxiety has a significant positive correlation with anxiety symptoms (Neimeyer, 2015). Feeling lonely not only has a significant positive correlation with anxiety symptoms (Gallagher, Prinstein, Simon \& Spirito, 2014; Ostovar, Allahyar, Aminpoor, Moafian, Nor, \& Griffiths, 2016) but also can predict these symptoms (Muyan, Chang, Jilani, Yu, Lin, \& Hirsch, 2016). Moreover, Seligman and Csikszentmihalyi suggested that meaninglessness in life correlates with anxiety symptoms. Since the study of the relationship between anxiety symptoms and all the components of confrontation with the existential issues has not been conducted yet, one of the objectives of the study is to fulfill this task.

One of the challenges of research studies is the possible influence of moderating variables on the relationship between two or more other variables (predictor and criterion). Therefore, the aim of the study was examining defense mecha- 
nisms as a moderating variable in the relationship between an individual's confrontation with existential issues and anxiety symptoms. This investigation can reveal the nature of the relationship between existential issues and anxiety symptoms. So, psychotherapists and psychologists can apprehend a more comprehensive understanding of anxious people who confronted with existential issues. Choosing defense mechanisms as a moderating variable in the relationship between an individual's confrontation with existential issues and anxiety symptoms can be traced to Yalom's view. He sees the individual's interaction with various components of the existential issues through different defense mechanisms. On the other hand, immature and neurotic defense mechanisms can lead to the symptoms of anxiety (Colovic, Tosevski, Mladenovic, Milosavljevic \& Munjiza, 2016; Freud, 2018; Punamäki, Kanninen, Qouta \& El-Sarraj, 2002; Waqas, 2015).

Defense mechanisms are a series of operations used by organisms to protect themselves from impulses and emotions. Defense mechanisms are defined as a set of mental operations to keep unacceptable thoughts, impulses, and desires out of the field of consciousness to protect people against growing anxiety, to increase self-esteem, or to protect self-integrity. Defense mechanisms are considered a part of personal performance, but the overutilization and the inappropriate use of specific defenses can lead to psychological anxiety (Cramer, 2015; McAdams, 1998).

Andrews et al., (1993) divided defense mechanisms into 3 categories: mature, immature, and neurotic mechanisms. The mature defensive style includes the mechanisms of sublimation, sense of humor, prediction, and suppression. The neurotic defense style consists of the defense mechanisms of undoing, pseudo-altruism, idealization, and reaction formation. The immature style includes the following defense mechanisms: projection, passive aggression, acting out, isolation, devaluation, autistic fantasy, denial, displacement, dissociation, splitting, rationalization, and somatization.

Therefore, concerning the effects of defense mechanisms on the components of confrontation with existential issues and anxiety symptoms, this study aimed to examine the moderating role of defense mechanisms in the relationship between confrontation with existential issues and anxiety symptoms.

\section{Methods}

\section{Study participants}

The participants of the present study included students at the Ferdowsi University of Mashhad in the academic year 2017-2018. According to the Krejcie-Morgan Table (Krejcie \& Morgan, 1970), 378 students were selected as an adequate sample size. However, because of the possibility of the distortion of some questionnaires, the initial sample size of 400 people was calculated.

\section{Study procedure}

The present research is a cross-sectional study. The participants were selected by the convenience sampling method. To control the fatigue and order effects, the scales of questionnaires were presented in two different orders. The inclusion criteria included their consent to participate in the research and studying at the Ferdowsi University of Mashhad. Regarding the ethical consideration, the researcher provided the necessary explanations about the aim of the study. Then, the researcher proposed the instructions for filling the questionnaires to each participant and, finally, asked them to participate in the research. They could choose not to answer a particular question and they were free to withdraw at any time during the study without giving a reason. By eliminating 11 incomplete or confused questionnaires, the number of samples was reduced to 389 students (218 male and 171 female students). The Mean \pm SD age of the male and female participants was 20.84 \pm 2.91 and 22.31 \pm 3.67 years, respectively. The Mean \pm SD age of all students was $21.48 \pm 3.33$ years. It took approximately 30 minutes to fill out the questionnaires.

\section{Study measures}

\section{Death Anxiety Scale (DAS)}

Templer designed Death Anxiety Scale (DAS) with 15 Yes/No questions, in which "Yes" represented the anxiety of death. The scores of the self-report scale range from 0 to 15 , and higher scores indicate more death anxiety. In American society, the test-retest reliability coefficient of the scale was found 0.83 and its concurrent validities with the Manifest Anxiety Scale and Beck Depression Inventory were found as 0.27 and 0.40 , respectively $(\mathrm{P}<0.001)$ (Templer, 1970). Rajabi and Bohrani stated that the reliability of this scale in Iranian society through the split-half method and internal consistency were found as 0.6 and 0.73 , respectively $(\mathrm{P}<0.001)$. Tavakolli and Ahmad Zadeh (2011). found that the reliability of the test via test-retest, split-half, and Cronbach's alpha society is $0.87,0.59$, and 0.75 , respectively.

\section{UCLA Loneliness Scale (Version 3)}

Russell et al., (1996) developed this scale for the first time. A 4-point response option scale ( $1=$ never, $2=$ rarely, $3=$ sometimes, $4=$ often) is scored based on the Likert- 
type scale. The Cronbach alpha reliability coefficient for the scale ranges from 0.89-0.94, and its reliability through the test-retest method in a 1-year frame is 0.73 . Significant correlations demonstrated the convergent validity of the scale with other tests (Russell, 1996). In Iranian society, the Cronbach alpha reliability coefficient of this scale is 0.89 . The correlation coefficient of the answers to the question about persistent loneliness is 0.55 , which is significant at the level of $\mathrm{P}<0.01$ and reflects the convergent validity of the scale. The divergent validity of this scale through its correlation $(r=0.67)$ with the Beck depression inventory $(\mathrm{P}<0.01)$ was confirmed (Bohayraei, Delavar \& Ahadi, 2010).

\section{Responsibility Scale of California Psychological Inventory}

California Psychological Inventory is a self-report scale created by Harrison G. Gough to assess the sustainability features of personality in the healthy population. This scale measures variables such as loyalty, responsibility, trustworthiness, achievement via conformance to rules and regulations, and believing the dominance of wisdom and rationality (Groth-Marnat, 2009). The test-retest coefficient of the questionnaire is $0.70(\mathrm{P}<0.001)$. The coefficient of internal consistency of scales ranges from 0.52 to 0.82 , representing the internal consistency of the scales of this research (Gough, 1987). Atefvahid et al., (2006) reported that the reliability of the scale in Iranian society is 0.57 and the test-retest reliability coefficient of the scale at a 2-week interval is $0.73(\mathrm{P}<0.001)$. Pasha and Gudarzian (2008) also stated that the reliability of this scale was found 0.76 by calculating the Cronbach alpha coefficient and 0.88 by using the split-half method.

\section{Meaning Life Questionnaire}

This scale is provided by Steger et al., (2006) to evaluate the significance of living or existence and effort to find meaning in life. Meaning life questionnaire consists of two scales, which evaluate the meaning in life and the search to find the meaning in life. According to Steger et al., (2006) the Cronbach alpha coefficients of subscales of meaning in life and searching for meaning are 0.07 and 0.73 , respectively. The convergent validity of the scale through its correlation with similar scales ranges from 0.61-0.74 $(\mathrm{P}<0.001)$. The test-retest reliability of the scale in Iran with a 2-week time interval for the subscales of meaning and searching for meaning were 0.84 and 0.74 , respectively $(\mathrm{P}<0.01)$. The Cronbach alpha values of searching for meaning and the meaning of life were 0.75 and 0.78 , respectively. So, it seems that this scale has satisfactory internal consistency (Eshtad, 2009).

\section{Depression Anxiety Stress Scale (DASS)}

Lovibond and Lovibond introduced the Depression Anxiety Stress Scale (DASS). It is a 21-item test that measures the symptoms of depression, anxiety, and stress. This scale is a valid instrument for assessing the symptoms of negative emotions, the reliability and validity of which have been confirmed in multiple studies (Antony, Bieling, Cox, Enns \& Swinson, 1998; Brown, Chorpita, Korotitsch \& Barlow, 1997; Daza, Novy, Stanley \& Averill, 2002; Lovibond, 1998; Norton, 2007). Besharat reported the Cronbach alpha coefficients of the DASS subscales (depression, anxiety, and stress) and the total number of DASS as $0.87,0.85,0.89$, and 0.91 , respectively. These coefficients confirm the internal consistency of the depression, anxiety, and stress scale at a good grade. The concurrent, convergent, and discriminant validities of DASS were calculated and approved through the simultaneous implementation of Beck depression inventory, Beck anxiety scale, positive and negative affect schedule, and mental health inventory of participants, as well as comparing the scores of general and clinical population groups (Besharat, 2005).

\section{Defense Style Questionnaire (DSQ)}

Andrews et al. was designed this questionnaire with 40 questions and scored based on a 9-point Likert-type scale (from strongly agree to strongly disagree). The questionnaire measured 20 defense mechanisms in terms of neurotic, mature, and immature defense mechanisms. Based on the applied questionnaires, it was revealed that inner consistency and validity measures for this questionnaire are adequate (Martin et al., 2019). The psychometric properties of the Persian version of the defense mechanisms questionnaire were investigated and confirmed (Besharat, 2007; Besharat, Sharifi \& Iravani, 2001).

In these studies, the Cronbach alpha coefficients for questions of each subscale of Defense Style Questionnaire (DSQ) ranged from 0.83-0.94 for mature style, 0.81-0.92 for immature style, and 0.79-0.91 for neurotic style. The internal consistency coefficients were confirmed for the subscales of DSQ. The test-retest reliability of DSQ was obtained for patient $(n=107)$ and normal samples $(n=248)$ at 2 to 6 week intervals from 0.73-0.87 for mature style, $0.71-0.84$ for immature style, and $0.69-0.78$ for neurotic style. These coefficients have confirmed the test-retest reliability of DSQ.

The convergent and discriminant validity of the Persian version of the questionnaire was calculated and approved through the simultaneous implementation of mental 
health inventory, inventory of interpersonal problems, neuroticism and extraversion personality subscales, and the positive and negative affect schedule in the case of both patients and normal groups (Besharat, 2007).

\section{Results}

Table 1 presents the Mean \pm SD scores of confrontation with existential issues, anxiety symptoms, and defense mechanisms by sex ratio and for the entire sample of students at Ferdowsi University in the academic year 2017 2018.

Table 2 presents the results of the Pearson correlation test. Anxiety symptoms have a direct and significant cor- relation with death, anxiety, and loneliness. They also have an indirect and significant correlation with responsibility and meaningfulness of life. Loneliness and death anxiety have a direct and indirect significant correlation with immature and mature defense mechanisms, respectively. Responsibility and meaningfulness of life have an indirect and direct correlation with immature and mature defense mechanisms, respectively.

To examine the moderating role of defense mechanisms in the relationship between confrontation with existential issues and anxiety symptoms, a set of stepwise and hierarchical regression analyses were separately conducted for each of 3 defense mechanisms (mature, neurotic, and immature). In this method, variables were entered

Table 1. Mean $\pm S D$ of variables and indicators

\begin{tabular}{|c|c|c|c|}
\hline \multirow{3}{*}{ Variables and Indicators } & \multicolumn{3}{|c|}{ Mean $\pm S D$} \\
\hline & \multicolumn{3}{|c|}{ Student } \\
\hline & Male & Female & All \\
\hline Death anxiety & $7.57 \pm 3.02$ & $8.92 \pm 3.25$ & $8.16 \pm 3.18$ \\
\hline Loneliness & $46.43 \pm 12.29$ & $40.24 \pm 10.74$ & $43.70 \pm 12.00$ \\
\hline Meaningfulness of life & $16.29 \pm 4.84$ & $16.68 \pm 4.69$ & $16.46 \pm 4.76$ \\
\hline Responsibility & $20.88 \pm 4.64$ & $19.56 \pm 3.38$ & $20.30 \pm 4.18$ \\
\hline Anxiety symptoms & $4.22 \pm 4.04$ & $3.56 \pm 3.76$ & $3.91 \pm 3.93$ \\
\hline Immature defense mechanisms & $4.61 \pm 0.91$ & $4.05 \pm 0.90$ & $4.37 \pm 0.95$ \\
\hline Neurotic defense mechanisms & $5.18 \pm 1.28$ & $4.77 \pm 1.15$ & $5.02 \pm 1.25$ \\
\hline Mature defense mechanisms & $5.42 \pm 1.10$ & $5.51 \pm 1.24$ & $5.47 \pm 1.17$ \\
\hline
\end{tabular}

Table 2. Correlation coefficient matrix of Variables

\begin{tabular}{|c|c|c|c|c|c|c|c|c|}
\hline Variables & 1 & 2 & 3 & 4 & 5 & 6 & 7 & 8 \\
\hline Death anxiety & 1 & & & & & & & \\
\hline Loneliness & 09.0 & 1 & & & & & & \\
\hline Responsibility & $0.1^{*}$ & -0.01 & 1 & & & & & \\
\hline Meaningfulness of life & $-0.14 * *$ & $-0.43^{* *}$ & $0.2^{* *}$ & 1 & & & & \\
\hline Anxiety symptoms & $0.11 *$ & $0.3^{* *}$ & $0.15-* *$ & $-0.2^{* *}$ & 1 & & & \\
\hline $\begin{array}{l}\text { Immature defense } \\
\text { mechanisms }\end{array}$ & $0.1^{*}$ & $0.14^{* *}$ & 0.06 & $-0.14 * *$ & $0.28 * *$ & 1 & & \\
\hline $\begin{array}{l}\text { Neurotic defense } \\
\text { mechanisms }\end{array}$ & 0.07 & -0.02 & $0.17^{* *}$ & $0.13^{* *}$ & 0.40 & $0.49 * *$ & 1 & \\
\hline $\begin{array}{l}\text { Mature defense } \\
\text { mechanisms }\end{array}$ & $-0.19 * *$ & $-0.27 * *$ & $0.19 * *$ & $0.13 * *$ & $-0.23 * *$ & 0.07 & $0.18^{* *}$ & 1 \\
\hline
\end{tabular}

* $\mathrm{P}<0.05$ 
Table 3. Hierarchical stepwise regression analysis to evaluate the moderating role of mature defense mechanisms in the relationship between confrontation with existential issues and anxiety symptoms

\begin{tabular}{ccccccccc}
\hline Model & \multicolumn{2}{c}{ Unstandardized Coefficients } & $\begin{array}{c}\text { Standardized } \\
\text { Coefficients Beta }\end{array}$ & $\mathbf{T}$ & $\mathbf{R}^{2}$ & $\Delta \mathbf{R}^{2}$ & $\Delta \mathbf{F}$ \\
\cline { 2 - 6 } & $\mathbf{B}$ & Std. Error & 0.018 & $0.155^{*}$ & 2.810 & 0.096 & 0.096 & $40.936^{*}$ \\
\hline 2 & 0.051 & -0.168 & $-0.182^{*}$ & -3.607 & 0.12 & 0.024 & $10.721^{*}$ \\
3 & -0.213 & 0.067 & $-0.152^{*}$ & -3.18 & 0.136 & 0.016 & $6.957^{*}$ \\
4 & 0.12 & 0 & $0.229^{*}$ & 4.254 & 0.175 & 0.039 & $18.1^{*}$ \\
\hline
\end{tabular}

Model 1. Predictor variable: loneliness;

Model 2. Predictor variable: loneliness and responsibility;

Model 3. Predictor variable: loneliness, responsibility, and mature defense mechanisms;

Model 4. Predictor variable: Loneliness, responsibility, mature defense mechanisms, and the moderating effect of mature defense mechanisms.

${ }^{*} \mathrm{P}<0.05$

into hierarchical regression analysis in 3 steps, including existential issues, one of the defense mechanisms, existential issues, and defense mechanism. According to stepwise, as the analysis method in this research, insignificant variables would be excluded from the model. During the process of stepwise and hierarchical regression analysis, each model only presents significant variables, and the final model is the most fitted.

Table 3 summarizes the examination of the moderating role of mature defense mechanisms. A comparison between models 3 and 4 shows that the moderating effect of mature defense mechanisms will increase the amount of $\mathrm{R}^{2}$ to $0.17\left(\Delta \mathrm{R}^{2}=0.039, \Delta \mathrm{F}=18.100\right.$, $\mathrm{P}=0.000)$. Therefore, model 4 shows that $3.9 \%$ of the observed variance in anxiety symptoms is explained owing to the moderating role of mature defense mechanisms. Moreover, the Beta coefficient showed that the moderating effect of mature defense mechanisms $(\beta=0.229, t=4.254, P=0.000)$ significantly explains the variance of anxiety symptoms based on loneliness and responsibility.

Table 4. Hierarchical stepwise regression analysis to evaluate the moderating role of neurotic defense mechanisms

\begin{tabular}{ccccccccc}
\hline Model & \multicolumn{2}{c}{ Unstandardized Coefficients } & $\begin{array}{c}\text { Standardized } \\
\text { Coefficients Beta }\end{array}$ & $\mathbf{T}$ & $\mathbf{R}^{\mathbf{2}}$ & $\mathbf{\Delta R}^{2}$ & $\Delta \mathbf{F}$ \\
\cline { 2 - 7 } & $\mathbf{B}$ & Std. Error & 0.018 & $0.168^{*}$ & 3.102 & 0.096 & 0.096 & $40.936^{*}$ \\
\hline 1 & 0.055 & 0.066 & $-0.182^{*}$ & -3.902 & 0.119 & 0.024 & $10.347^{*}$ \\
\hline 3 & -0.256 & -0.117 & 0.077 & -0.095 & -1.528 & 0.129 & 0.01 & $4.274^{* *}$ \\
\hline 4 & 0.145 & 0.000 & $0.33^{*}$ & 4.739 & 0.177 & 0.048 & $22.459^{*}$ \\
\hline
\end{tabular}

Model 1. Predictor variable: Loneliness;

PRACTICE In
CLINICAL PSYCH $\odot$ LOGY

Model 2. Predictor variable: Loneliness and responsibility;

Model 3. Predictor variable: Loneliness, responsibility, and death anxiety;

Model 4. Predictor variable: Loneliness, responsibility, death anxiety, and moderating effect of neurotic defense mechanisms.

* $\mathrm{P}<0.05$ 
Table 5. Hierarchical stepwise regression analysis to evaluate the moderating role of immature defense mechanisms

\begin{tabular}{|c|c|c|c|c|c|c|c|}
\hline \multirow{2}{*}{ Model } & \multicolumn{2}{|c|}{ Unstandardized Coefficients } & \multirow{2}{*}{$\begin{array}{c}\text { Standardized Coefficients } \\
\text { Beta }\end{array}$} & \multirow{2}{*}{$\mathbf{T}$} & \multirow{2}{*}{$\mathbf{R}^{\mathbf{2}}$} & \multirow{2}{*}{$\Delta \mathbf{R}^{2}$} & \multirow{2}{*}{$\Delta \mathbf{F}$} \\
\hline & B & Std. Error & & & & & \\
\hline 1 & 0.04 & 0.018 & $0.121^{*}$ & 2.177 & 0.096 & 0.096 & $40.936 * *$ \\
\hline 2 & 0.446 & 0.226 & $0.108 *$ & 1.974 & 0.125 & 0.029 & $12.821^{* *}$ \\
\hline 3 & -0.249 & 0.065 & $-0.178 * *$ & -3.86 & 0.153 & 0.028 & $12.737 * *$ \\
\hline 4 & 0.123 & 0 & $0.261 * *$ & 4.415 & 0.194 & 0.041 & $9.488 * *$ \\
\hline
\end{tabular}

Model 1. Predictor variable: Loneliness;

Model 2. Predictor variable: Loneliness and responsibility;

Model 3. Predictor variable: Loneliness, responsibility, and immature defense mechanisms;

Model 4. Predictor variable: Loneliness, responsibility, immature defense mechanisms, and moderating effect of immature defense mechanisms.

* $\mathrm{P}<0.05$

** $\mathrm{P}<0.01$

Table 4 presents the results of moderating regression analysis to investigate the moderating role of neurotic defense mechanisms in the relationship between confrontation with existential issues and anxiety symptoms. The comparison between models 3 and 4 shows that the moderating effect of neurotic defense mechanisms has significantly increased the amount of $\mathrm{R}^{2}$ to 0.04 $\left(\Delta \mathrm{R}^{2}=0.048, \Delta \mathrm{F}=22.459, \mathrm{P}=0.000\right)$. Moreover, the Beta coefficient showed that the moderating effect of neurotic defense mechanisms $(\beta=0.330, t=4.739, \mathrm{P}=0.000)$ could significantly explain the variance of anxiety symptoms based on loneliness, responsibility, and death anxiety.

Table 5 presents the moderating role of immature defense mechanisms in the relationship between confrontation with existential issues and anxiety symptoms. Model 4 shows the degree of the relationship between predictor variables of loneliness and immature defense mechanism's responsibility after entering the moderating effect of immature defense mechanisms. The comparison between models 3 and 4 shows that the moderating effect of immature defense mechanisms has significantly increased the amount of $\mathrm{R}^{2}$ to $0.04\left(\Delta \mathrm{R}^{2}=0.041\right.$, $\Delta \mathrm{F}=19.488, \mathrm{P}=0.000)$. The moderating effect of immature defense mechanisms $(\beta=0.261, \mathrm{t}=4.415, \mathrm{P}=0.000)$ can significantly explain the variance of anxiety symptoms based on loneliness and responsibility.

\section{Discussion}

Defense mechanisms could moderate the relationship between confrontation with existential issues and anxiety

symptoms. To explain these findings, we can point out to the main core of confrontation with existential issues. Ultimate concerns or existential issues represent death, loneliness, freedom, and the meaninglessness of the individual in relation to existence. These facts conflict with the desires of immortality, real relationships, meaningfulness, and the structured situation in existence. People are aware of these facts consciously and unconsciously; thus, alive individuals are confronted with the facts intentionally or unintentionally (Zafirides, 2013).

When a person is unable to accept these facts, the pressure on him or her increases. Against suffering from this confrontation, self uses defense mechanisms of distorting reality, including immature and neurotic defense mechanisms. The appropriate use of these mechanisms provides psychological security, but their excessive use prevents a person's growth. Moreover, by using ineffective defense mechanisms, the risk of developing emotional disorders, especially anxiety, would increase (Zafirides, 2013). Therefore, their moderating effect in the relationship between an individual's confrontation with existential issues and mental disorders will increase (Yalom, 1980). In contrast, whenever a person fully accepts the givens of existence, influenced by the acceptance of reality, this person will use better defense mechanisms consistent with the realities (or mature defense mechanisms). Thus, the moderating effect of these mechanisms leads to decreasing anxiety symptoms in the confrontation with existential issues.

The results specified that just loneliness and responsibility could predict anxiety symptoms by the moderating role 
of defense mechanisms. Both the loneliness and responsibility are more objective and specified existential issues than death anxiety and meaninglessness. Besides, defense mechanisms are absolutely and healthy and unhealthy ways for coping with existential issues; they are also objective, like loneliness and responsibility. Therefore, these objective existential issues are moderated by defense mechanisms as objective coping ways (Punamäki et al., 2002).

The findings of this study have important theoretical and practical implications. In theory, this research investigated risk factors and the ways to create anxiety symptoms in a new way. The findings of this study confirmed the importance and effectiveness of an individual's confrontation with existential issues in developing anxiety symptoms. It was shown that a variety of defense mechanisms would moderate this confrontation. Therefore, by focusing on how individuals cope with existential issues, they should be helped to reduce the use of immature and neurotic defense mechanisms and increase the use of mature defense mechanisms. In this way, besides reducing the economic and mental costs of anxiety, solutions can be found based on the existential and psychoanalytic concepts to prevent and treat anxiety.

The present study had some limitations. The sample was limited to students at the Ferdowsi University of Mashhad in the academic year of 2015-2016. To generalize the results to the entire society, this limitation should be considered. Another limitation of this study was its self-report format and retrospective method, in the sense that their current mood and relations might influence answers and might not reflect their usual conditions. Also, a negative mood would remind the negative points and weaknesses. The third limitation of the present study was using the correlational design, which limited the possibility of the extraction of the etiology interpretations.

Anxiety symptoms were influenced by confrontation with existential issues. Defense mechanisms moderated this relationship.

\section{Ethical considerations}

\section{Compliance with ethical guidelines}

All participants were informed about the study objectives and its potential benefit and damages and they were assured of the confidentiality of their information. They were free to leave the study at any time.

\section{Funding}

This research did not receive any specific grant from funding agencies in the public, commercial, or not-forprofit organizations.

\section{Authors' contributions}

All authors contributed equally in preparing this article.

\section{Conflict of interest}

The authors declare no conflict of interest

\section{References}

Andrews, G., Singh, M., \& Bond, M. (1993). The defense style questionnaire. Journal of Nervous and Mental Disease, 181(4) 246-56. [DOI:10.1097/00005053-199304000-00006] [PMID]

Antony, M. M., Bieling, P. J., Cox, B. J., Enns, M. W., \& Swinson, R. P. (1998). Psychometric properties of the 42 -item and 21item versions of the Depression Anxiety Stress Scales (DASS) in clinical groups and a community sample. Psychological Assessment, 10(2), 176-81. [DOI:10.1037/1040-3590.10.2.176]

Atefvahid, M. K., Nasr Esfahani, M., Fathollahi, P., \& Shojaee, S. M. R. (2006). [Standardization of the Persian version of the California Psychological Inventory (PCI) (Persian)]. Iranian Journal of Psychiatry and Clinical Psychology, 11(4), 371-8.

Besharat, M. A. (2005). Examining the properties of Depression Anxiety Stress Scale (DASS-21) in clinical samples and the general population. Research Report. Tehran: Tehran University.

Besharat, M. A. (2007). Evaluation the psychometric properties of Defense Styles Questionnaire. Research Report. Tehran: Tehran University.

Besharat, M. A., Sharifi, M., \& Iravani, M. (2001). [An investigation of the relationship between attachment styles and defense mechanisms (Persian)]. Journal of Psychology, 5(3), 277-89.

Bohayraei, H., Delavar, A., \& Ahadi, H. (2010). Standardization of third edition of Loneliness Scale UCLA (UCLA) in students' community in Tehran. Applied Psychology, 1, 6-18.

Brown, T. A., Chorpita, B. F., Korotitsch, W., \& Barlow, D. H. (1997). Psychometric properties of the Depression Anxiety Stress Scales (DASS) in clinical samples. Behavior Research and Therapy, 35(1), 79-89. [DOI:10.1016/S0005-7967(96)00068-X]

Colovic, O., Tosevski, D. L., Mladenovic, I. P., Milosavljevic, M., \& Muniza, A. (2016). Defense mechanisms in "pure" anxiety and "pure" depressive disorders. The Journal of Nervous and Mental Disease, 204(10), 746-51. [DOI:10.1097/ NMD.0000000000000559] [PMID]

Cooper, M. (2016). Existential therapies. London: Sage Publications Ltd. 
Cramer, P. (2015). Understanding defense mechanisms. Psychodynamic Psychiatry, 43(4), 523-52. [DOI:10.1521/ pdps.2015.43.4.523] [PMID]

Daza, P., Novy, D. M., Stanley, M. A., \& Averill, P. (2002). The depression anxiety stress scale-21: Spanish translation and validation with a Hispanic sample. Journal of Psychopathology and Behavioral Assessment, 24(3), 195-205.

Eshtad, A. (2009). Studying the effectiveness of cognitive group therapy on students' subjective well - being. Master thesis in Clinical Psychology, Tehran Psychiatric Institute.

Freud, A. (2018). The ego and the mechanisms of defence. London: Routledge. [DOI:10.4324/9780429481550]

Gallagher, M., Prinstein, M. J., Simon, V., \& Spirito, A. (2014). Social anxiety symptoms and suicidal ideation in a clinical sample of early adolescents: Examining loneliness and social support as longitudinal mediators. Journal of Abnormal Child Psychology, 42(6), 871-83. [DOI:10.1007/s10802-013-9844-7] [PMID] [PMCID]

Gough, H. G. (1987). California psychological inventory: Administrator's guide. Palo Alto, CA: Consulting Psychologists Press.

Groth-Marnat, G. (2009). Handbook of psychological assessment. Hoboken: John Wiley \& Sons.

Krejcie, R. V., \& Morgan, D. W. (1970). Determining sample size for research activities. Educational and Psychological Measurement, 30(3), 607-10. [DOI:10.1177/001316447003000308]

Langs, R. (2018). Death anxiety and clinical practice. London: Routledge. [DOI:10.4324/9780429473579]

Lovibond, P. F. (1998). Long-term stability of depression, anxiety, and stress syndromes. Journal of Abnormal Psychology, 107(3), 520-6. [DOI:10.1037/0021-843X.107.3.520] [PMID]

Lovibond, S. H., \& Lovibond, P. F. (1995). Manual for the Dpression Anxiety Stress Scales. Sydney: Psychological Foundation Monograph. [DOI:10.1037/t01004-000]

Martin, L., Hargitai, R., Hupuczi, E., Rózsa, S., Birkás, B., \& Varga, J., et al. (2019). [Defense Style Questionnaire (DSQ-40): Factors, validity and reliability (Hungarian)]. Psychiatria Hungarica: A Magyar Pszichiátriai Társaság tudományos folyoirata, 34(1), 19-33. [PMID]

May, R., \& Yalom, I. (2005). Existential psychotherapy. In R. J. Corsini, \& D. Wedding (Eds.), Current psychotherapies (pp. 269298). $7^{\text {th }}$ ed. Belmont, CA: Brooks/Cole.

McAdams, D. P. (1998). The role of defense in the life story. Journal of Personality, 66(6), 1125-46. [DOI:10.1111/1467-6494.00044]

Muyan, M., Chang, E. C., Jilani, Z., Yu, T., Lin, J., \& Hirsch, J. K. (2016). Loneliness and negative affective conditions in adults: Is there any room for hope in predicting anxiety and depressive symptoms? The Journal of Psychology, 150(3), 333-41. [DOI :10.1080/00223980.2015.1039474] [PMID]

Neimeyer, R. A. (Ed.). (2015). Death anxiety handbook: Research, instrumentation, and application. New York: Taylor \& Francis. [DOI:10.4324/9781315800813] [PMCID]

Norton, P. J. (2007). Depression Anxiety and Stress Scales (DASS-21): Psychometric analysis across four racial groups. Anxiety, Stress \& Coping, 20(3), 253-65. [DOI:10.1080/10615800701309279] [PMID]
Ostovar, S., Allahyar, N., Aminpoor, H., Moafian, F., Nor, M. B. M., \& Griffiths, M. D. (2016). Internet addiction and its psychosocial risks (depression, anxiety, stress and loneliness) among Iranian adolescents and young adults: A structural equation model in a cross-sectional study. International Journal of Mental Health and Addiction, 14, 257-67. [DOI:10.1007/ s11469-015-9628-0]

Pasha, G. R., Gudarzian, D. (2008). [The relationships of identity styles, moral development and responsibility in Andimeshk Payamnur University (A.P.U) students (Persian)]. Journal of Social Psychology (New Findings in Psychology), 2(8), 87-99.

Punamäki, R. L., Kanninen, K., Qouta, S., \& El-Sarraj, E. (2002). The role of psychological defences in moderating between trauma and post-traumatic symptoms among Palestinian men. International Journal of Psychology, 37(5), 286-96.

Rajabi, G. R., \& Bohrani, M. (2002). [Item factor analysis of the Death Anxiety Scale (Persian)]. Journal of Psychology, 5(4), 331-44.

Roy-Byrne, P. (2015). Treatment-refractory anxiety; definition, risk factors, and treatment challenges. Dialogues in Clinical Neuroscience, 17(2), 191-206. [PMID] [PMCID]

Russell, D. W. (1996). UCLA Loneliness Scale (Version 3): Reliability, validity, and factor structure. Journal of Personality Assessment, 66(1), 20-40. [DOI:10.1207/s15327752jpa6601_2] [PMID]

Russell, D., Peplau, L. A., \& Ferguson, M. L. (1978). Developing a measure of loneliness. Journal of Personality Assessment, 42(3), 290-4. [DOI:10.1207/s15327752jpa4203_11] [PMID]

Sadock, B. J., Sadock, V. A., \& Ruiz, P. (2015). Kaplan and Sadock's synopsis of psychiatry: Behavioral sciences/clinical psychiatry. $11^{\text {th }}$ ed. Philadelphia: Wolters Kluwer.

Seligman, M. E., \& Csikszentmihalyi, M. (2014). Positive psychology: An introduction. Dordrecht: Springer. [DOI:10.1007/97894-017-9088-8_18]

Steger, M. F., Frazier, P., Oishi, S., \& Kaler, M. (2006). The meaning in life questionnaire: Assessing the presence of and search for meaning in life. Journal of Counseling Psychology, 53(1), 80-93. [DOI:10.1037/0022-0167.53.1.80]

Tavakoli, M. A., \& Ahmadzadeh, B. (2011). Investigation of validity and reliability of templer Death Anxiety Scale. Thought $\mathcal{E}$ Behavior in Clinical Psychology, 6(21), 72-80.

Teimouri, Y., Goetze, J., \& Plonsky, L. (2019). Second language anxiety and achievement: A meta-analysis. Studies in Second Language Acquisition, 41(2), 363-87. [DOI:10.1017/ S0272263118000311]

Templer, D. I. (1970). The construction and validation of a Death Anxiety Scale. Journal of General Psychology, 82(2d Half), 16577. [DOI:10.1080/00221309.1970.9920634] [PMID]

Waqas, A., Rehman, A., Malik, A., Muhammad, U., Khan, S. \& Mahmood, N. (2015). Association of ego defense mechanisms with academic performance, anxiety and depression in medical students: A mixed methods study. Cureūs, 7(9), e337. [DOI:10.7759/cureus.337] [PMID] [PMCID]

Yalom, I. D. (1980). Existential psychotherapy. New York: Basic Books.

Zafirides, P. (2013). Existential psychotherapy: How the search for meaning can heal us. In K. D. Markman, T. Proulx, \& M. 
J. Lindberg (Eds.), The psychology of meaning. New York: American Psychological Association Press. 